\title{
Key climate indices in Switzerland; expected changes in a future climate
}

\author{
Elias M. Zubler • Simon C. Scherrer • \\ Mischa Croci-Maspoli • Mark A. Liniger • \\ Christof Appenzeller
}

Received: 29 May 2013 / Accepted: 19 December 2013 / Published online: 18 January 2014

(C) Springer Science+Business Media Dordrecht 2014

\begin{abstract}
Climate indices facilitate the interpretation of expected climate change impacts for many sectors in society, economy, and ecology. The new localized data set of climatic change signals for temperature and precipitation presented by Zubler et al. (Clim Change, 2013) is applied for an analysis of frequently used climate indices in Switzerland. The indices considered are: number of summer days and tropical nights, growing season length, number of frost days and ice days, heating and cooling degree days, and the number of days with fresh snow. For the future periods 2020-49, 2045-74 and 2070-2099 the indices are computed using a delta-change approach based on the reference period 19802009 for the emission scenarios A1B, A2, and RCP3PD. The scenario data suggest the following relevant findings: (1) a doubling of the number of summer days by the end of the century under the scenarios A1B and A2, (2) an appearance of tropical nights even above $1500 \mathrm{~m}$ asl, (3) a possible reduction of the number of frost days by more than 3 months at altitudes higher than $2500 \mathrm{~m}$ asl, (4) a decline of heating degree days by about $30 \%$ until the end of the century, and (5) the near disappearance of days with fresh snow at low altitudes. It is also shown that the end-of-the-century projections of all indices strongly depend on the chosen emission scenario.
\end{abstract}

Electronic supplementary material The online version of this article (doi:10.1007/s10584-013-1041-8) contains supplementary material, which is available to authorized users.

E. M. Zubler $(\bowtie) \cdot$ S. C. Scherrer · M. Croci-Maspoli · M. A. Liniger · C. Appenzeller Federal Office of Meteorology and Climatology MeteoSwiss, Krähbühlstrasse 58, 8044 Zurich, Switzerland

e-mail: elias.zubler@meteoswiss.ch

S. C. Scherrer

e-mail: simon.scherrer@meteoswiss.ch

M. Croci-Maspoli

e-mail: mischa.croci-maspoli@meteoswiss.ch

M. A. Liniger

e-mail: mark.liniger@meteoswiss.ch

C. Appenzeller

e-mail: christof.appenzeller@meteoswiss.ch 
Keywords Downscaling - Climate change - ALPS - Temperature · Precipitation · Scenario $\cdot$ Switzerland · Indices $\cdot$ Summer days $\cdot$ Frost days $\cdot$ Heating degree days $\cdot$ Wet days $\cdot$ Tropical nights

\section{Introduction and motivation}

Climate indices facilitate the interpretation of the impacts of climatic change on ecology, economy and society. Many societal challenges and sectors such as public services, infrastructure, food security, water, energy, transportation, tourism and health depend on climatological conditions (Karl et al. 1999; Peterson et al. 2001; Klein Tank et al. 2009). The impacts of climate change on these conditions are likely to vary between the different climatic regions of Switzerland.

The Expert Team on Climate Change Detection and Indices (ETCCDI), which is the joint responsibility of the World Meteorological Organization (WMO), the World Climate Research Programme (WCRP) and the Joint Technical Commission for Oceanography and Marine Meteorology (JCOMM), has defined a set of indices that describe the manifold facets of climatic change (Klein Tank et al. 2009). In the present study, we evaluate the future development of some key indices over Switzerland for the periods 2020-49, 2045-74 and 2070-99 with respect to the reference period 1980-2009, using the spatially localized gridded data set providing probabilistic temperature and precipitation change signals presented by Zubler et al. (2013). In accordance with the CH2011 initiative, the analysis includes projections for the greenhouse gas emission scenarios A1B, A2, and RCP3PD (CH2011 2011). The following indices are considered here:

Number of summer days: Average number of days per year with maximum temperatures $\geq 25^{\circ} \mathrm{C}$. The number of summer days increased at some stations in Central Europe by 2-4 days per decade from 1946 to 1999 (Klein Tank and Können 2003). For example, this index is relevant for the public health sector and tourism.

Number of tropical nights: Average number of days per year with minimum temperatures $\geq 20^{\circ} \mathrm{C}$. Days with such high minimum temperatures can become a health problem for the elderly population, as the body cannot cool down after an already hot day (Cerutti et al. 2006; Kovats et al. 2004; Fischer and Schär 2010). Tropical nights are expected to increase in Central Europe by about 10-25 on average between today and the end of the 21 st century in ensemble simulations with a global climate model assuming two different business-as-usual scenarios (Sillmann and Roeckner 2008).

Number of frost days: Average number of days per year with minimum temperatures $<0{ }^{\circ} \mathrm{C}$. Klein Tank and Können (2003) show that the number of frost days has been significantly decreasing in Central Europe from 1946 to 1999 by about 4-6 days per decade. Frost days are strongly anti-correlated with the growing season length (Frich et al. 2002), thus having impact on agriculture and ecology, but also transportation (e.g., road safety).

Number of ice days: Average number of days per year with maximum temperatures < $0{ }^{\circ} \mathrm{C}$. This index is likely not only of interest to geologists and glaciologists, as days with temperatures below the melting point are important for glaciers and permafrost sustainability. In addition, the transport and housing sector may be affected by a changing number of ice days, in particular when reduced slope stability due to permafrost damage causes more mud slides (Dramis et al. 1995; Gruber et al. 2004; Gruber and Haeberli 2007; Krautblatter et al. 2013). 
Thermal growing season length: Average number of days in a year between the first occurrence of a 6-day period with daily mean temperatures $>5{ }^{\circ} \mathrm{C}$ and the first occurrence after July 1 of a 6-day period with daily mean temperatures $<5{ }^{\circ} \mathrm{C}$. This index is important for agriculture and ecology. At the same time it has to be kept in mind that the growing season length is plant-specific and is influenced by other factors that control frost resistance and growth (Levitt 1962).

Heating degree days: Annual average sum of differences between outside daily mean air temperature $\left(T_{a i r, i}\right)$ and the base temperature inside the building $\left(T_{\text {room }}=20{ }^{\circ} \mathrm{C}\right)$. Formally, heating degree days (HDD) can be defined in different ways. One common definition is as follows (e.g., Christenson et al. 2006):

$$
\mathrm{HDD}=\sum_{i=1}^{n} d_{i}\left(T_{\text {room }}-T_{a i r, i}\right)
$$

with $d_{i}=1$ if $T_{a i r, i}<12{ }^{\circ} \mathrm{C}$ or else $d_{i}=0$. Here, the threshold temperatures are based on the Swiss SIA norm 381/3 (Swiss Association of Engineers and Architects 1982). The international definition uses only $18.3^{\circ} \mathrm{C}$ as threshold (Peterson et al. 2001). Unit: Kd ('Kelvin-days'). The energy sector is mostly interested in changes of heating degree days, since the latter can be directly related to changes in energy consumption due to heating of buildings (Christenson et al. 2006).

Cooling degree days: Annual average sum of differences between outside daily mean air temperature $\left(T_{\text {air }, i}\right)$ and the base temperature $\left(T_{\text {cooling }}\right)$ of $18.3^{\circ} \mathrm{C}$ (American Society of Heating Refrigerating and Air-Conditioning Engineers 2001), above which cooling is assumed to be needed in buildings. In a formal sense, cooling degree days (CDD) are expressed by

$$
\mathrm{CDD}=\sum_{i=1}^{n} d_{i}\left(T_{\text {air }, i}-T_{\text {cooling }}\right)
$$

Here, $d_{i}=1$ if $T_{a i r, i}>T_{\text {cooling }}$ or else $d_{i}=0$. Unit: Kd.

Number of days with snowfall: Average number of days per year with a minimum of 1 $\mathrm{cm} \mathrm{d}^{-1}$ of snowfall. This index is analyzed because winter tourism is an important branch of the Swiss economy and depends strongly on the availability of snow. Air and road traffic administration is also affected by days with snowfall. Marty (2008) and Serquet et al. (2011) show that after 1980 a shift in the snow regime of Switzerland caused a reduction of the probability for days with snowfall by as much as $50 \%$ below $800 \mathrm{~m}$ asl with no clear trend since. In a warming climate, however, one can expect the number of days with snowfall to decrease further.

The full list of core indices defined by WMO is provided by Peterson et al. (2001). The list of indices taken into account in the present study is not exhaustive. The choice is based on indices that are believed to be of major importance for decision-making authorities and the climate impact modeling community, because these indices in particular illustrate the potential consequences of climate change in Switzerland in the near future and towards the end of the century.

Given the complex topography of Switzerland, the country can be split into several regions with different climatic characteristics (Schüepp and Gensler 1980; Baeriswyl and Rebetez 1997) and responses to greenhouse gas emissions (Zubler et al. 2013). Therefore, a detailed spatial analysis of the aforementioned indices is provided in this article. According to our knowledge, it is the first study to quantify changes in a large variety of climatic indices on such high spatial resolution for Switzerland. 
The article is structured as follows: Section 2 briefly describes the data and methods. Section 3 shows the results that are discussed in Section 4.

\section{Data and methods}

\subsection{General remarks}

Climate indices for the reference period (1980-2009) are calculated using gridded fields of observed daily mean temperature produced at MeteoSwiss. The grid data set was constructed from 90-100 station observations for each day using a novel deterministic spatial interpolation method (Frei 2013). The method adopts a non-linear parametric function for the vertical temperature profiles, which allows to model meso-scale inversion layers, surface heated boundary layers and other non-linearities explicitly. The method also involves a weighting scheme with non-Euclidean distances, which allows to retain thermal phenomena of more local extent, such as warm anomalies due to Foehn and valley-scale cold pools. Errors of the spatial interpolation range between $0.5^{\circ} \mathrm{C}$ over flat and hilly terrain in summer to $1.5^{\circ} \mathrm{C}$ in the Alps in winter (Frei 2013).

Gridded precipitation data at the resolution of $2 \mathrm{~km}$ is produced at MeteoSwiss as well. The product (RhiresD) is based on daily precipitation totals measured at the high-resolution rain-gauge network of MeteoSwiss. It uses all quality checked station measurements available for a particular day to ensure maximum effective resolution and accuracy. For more information on the interpolation method we refer to Frei and Schär (1998) and references therein.

For the same 2-km grid, Zubler et al. (2013) downscaled delta-change signals from the ENSEMBLES project (van der Linden and Mitchell 2009) and CH2011 initiative (Fischer et al. 2011), which are available for download (http://data.c2sm.ethz.ch/dataset/ch2011/). Here, a simple delta-change approach (Bosshard et al. 2011) is used to combine the gridded daily observations in the reference period with the mean change signals to obtain possible future temperature projections in the periods 2020-49, 2045-74 and 2070-2099. For that purpose, third-order harmonic fits are applied to the seasonal mean change signals of Zubler et al. (2013) in order to obtain a smooth annual cycle of daily mean temperature change. The method is equal to the one used in CH2011 (2011). It is constructed such that curvature of the annual cycle is minimized while the seasonal means are conserved.

For the mean change signals, three different estimates from the $\mathrm{CH} 2011$ scenarios are available: a lower, a median and an upper estimate. The three estimates have been derived from probabilistic information based on Bayesian calculations performed by Fischer et al. (2011) and Zubler et al. (2013), based on a method by Buser et al. (2009). The lower, median and upper scenario were initially derived from the $2.5 \%$-, $50 \%$ - and $97.5 \%$-quantiles but are not interpreted in a strict probabilistic way, mainly because of the large sensitivity of the results to model projection uncertainty, as highlighted by Fischer et al. (2011). For a detailed description of their method, the article of Fischer et al. (2011) is referred to.

The downscaling procedure of Zubler et al. (2013) relies on a kriging interpolation with external drift of ENSEMBLES mean change patterns, downscaling the coarse $25-\mathrm{km}$ signal onto the 2-km MeteoSwiss grid. Figure 1 shows the topography of the $2-\mathrm{km}$ grid as well as the main regions for which the indices have been analyzed in detail. Hence, the localized climate change signal is given as the sum of a deterministic part (multiple linear regression or trend) and a stochastic part (kriging interpolation of the regression residuals). The trends are computed on the ENSEMBLES multi-model mean change patterns that are 


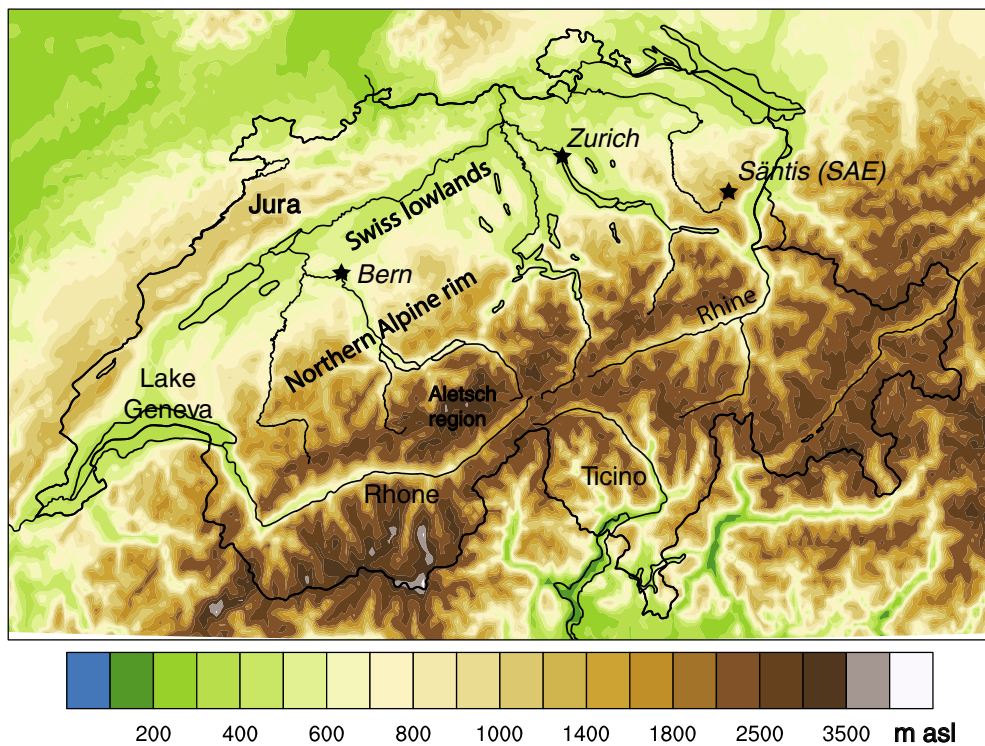

Fig. 1 Topography of the 2-km grid (m asl) and outline of Switzerland with the main regions discussed within this article

first scaled for each individual estimate such that regional means are consistent with the respective $\mathrm{CH} 2011$ estimates. The geographical coordinates latitude, longitude and height serve as linear predictors. The considered scenarios are the two SRES scenarios A1B and A2, both with business-as-usual characteristics (Solomon et al. 2007), and the strong mitigation scenario RCP3PD (Meinshausen et al. 2011). The A1B-scenario assumes technological progress that leads to emission reductions beyond 2050, whereas under A2 greenhouse gas emissions are continuously rising. Note, that the A2 and RCP3PD projections are based on pattern-scaling of the A1B-scenario using global mean temperature (Fischer et al. 2011).

The indices are computed as annual average over all 30 years of the reference period, using the daily mean, minimum or maximum temperature and 24-h accumulated precipitation on the 2-km grid. The daily delta-change signals are added to the reference years in order to obtain the future values for the respective indices. This is an important caveat of the present study since changes in variability and extremes are not accounted for.

\subsection{Diagnosing the number of days with snowfall}

Precipitation can fall as snow in environments with ambient temperatures up to $6{ }^{\circ} \mathrm{C}$ (Steinacker 1983). Whether the melting process starts at the $0{ }^{\circ} \mathrm{C}$-isoline is heavily dependent on the dryness of the atmosphere. Different methods exist to determine the snowfall level from atmospheric quantities such as equivalent potential temperature or relative topography (Steinacker 1983). The approach used here to quantify the number of days per year with more than $1 \mathrm{~cm}$ of snowfall is remarkably simple, given only by the daily mean temperature and daily precipitation sum from the gridded data set. Other information, such as humidity, is currently not available in gridded form. 
Based on sensitivity studies, as to which temperature criterion performed best, a day with snowfall is well approximated by a daily mean temperature colder than $2{ }^{\circ} \mathrm{C}$ and, in addition, more than $1 \mathrm{~mm}$ of precipitation (wet day).

For a validation of this method, the number of days with snowfall are computed for each year of the reference period (1980-2009) and 46 stations of the National Basic Climatological Network (NBCN) of MeteoSwiss (Begert et al. 2007). In order to approximate the station location with the gridded data, the inverse-distance-weighted mean of the four closest grid points is used. The agreement with observed snowfall days (Fig. 2) is very good (mean bias $=-0.23$ days, residual standard error $=11.5$ days, Spearman correlation $=$ $0.93)$. There is a certain tendency to overestimate the number of snow days at small observed values and a tendency to underestimate at the stations with large numbers of snow days. The bias may be partly induced by the inverse-distance-weighted values from the gridded data set. At high stations in the Alps, the use of the smoothed 2-km topography is likely to cause the abovementioned underestimation because the station is likely positioned higher than the four closest grid-points used for comparison. Vice versa for low stations.

Although the days with snowfall are estimated in a very simple manner, even interannual variability and the trends are represented to some extent. Figure 3 shows the interannual fluctuations of the number of snowfall days around the mean value for two stations (see figure caption for more detail). A significant $(\mathrm{p}<0.05)$ linear trend \pm 1 standard deviation of $-8.9 \pm 2.7(-5.3 \pm 2.5)$ days per decade is found for the mountainous station at Säntis SAE (2504 $\mathrm{m}$ asl) in the observations (simple approximation). The main causes for the discrepancy between the two linear trends are the underestimation in the early 1980s and the overestimation of snowfall days between 2006 and 2009.

We compared the ratio of snowfall days and wet days during winter in the reference period with the work of Serquet et al. (2011) and found good agreement with their

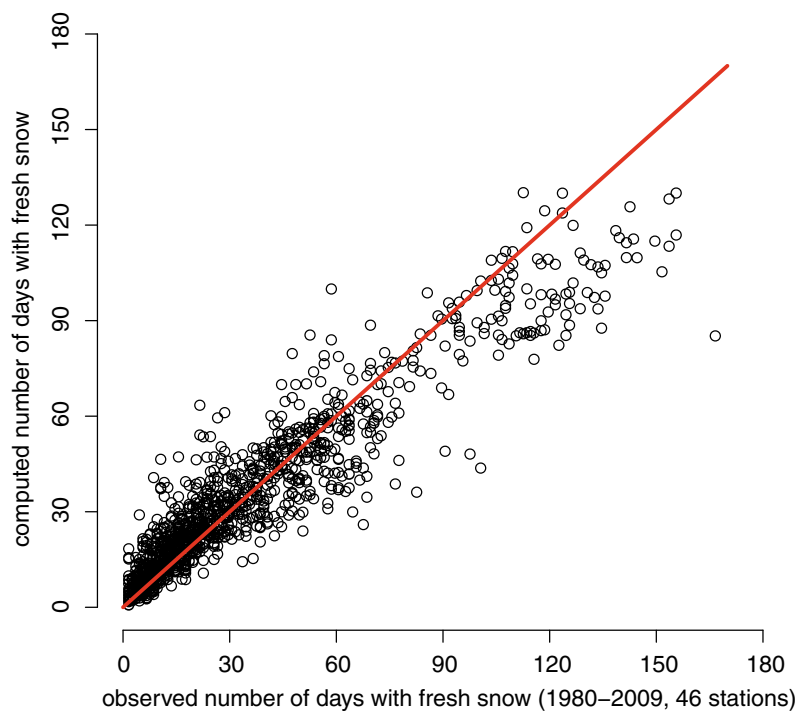

Fig. 2 Computed versus observed total annual number of days with fresh snow (more than $1 \mathrm{~cm}$ of snowfall) in the period 1980-2009. Observations are based on the MeteoSwiss NBCN stations. Results for 46 stations with continuous snowfall measurements are shown. Each black circle represents one year of a station (for details see text). The red line is the 1:1-ratio indicating perfect match of observations and computed number of days with snowfall 
(a) Zurich-Fluntern (SMA)

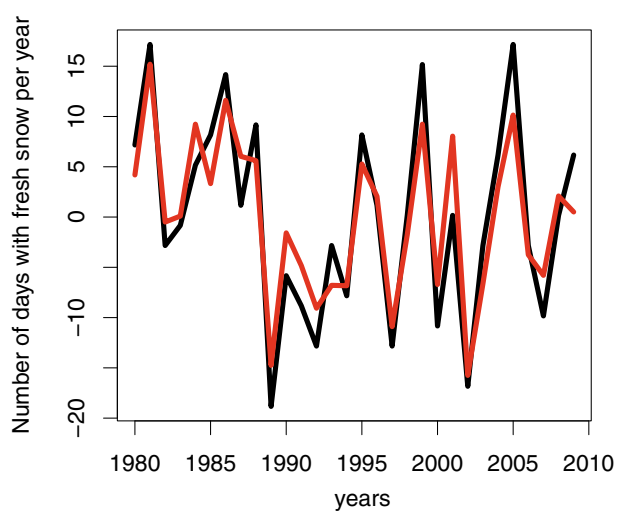

(b) Säntis SAE

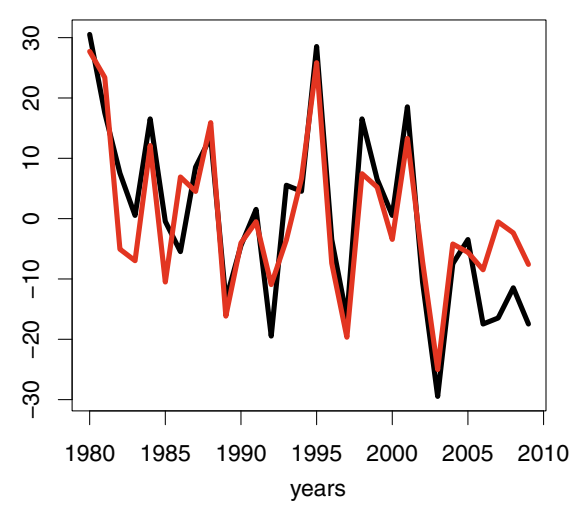

Fig. 3 Computed and observed yearly anomaly of the number of days with more than $1 \mathrm{~cm}$ of snowfall. The mean bias has been subtracted from the modeled values. Stations: a MeteoSwiss in Zurich-Fluntern (SMA) at $556 \mathrm{~m}$ asl and b Saentis (SAE), an exposed mountain peak in the eastern Swiss Alps at $2504 \mathrm{~m}$ asl. For SAE (SMA), the Spearman correlation coefficient is $0.83(0.92)$

observations during the period 1980-2005, providing an additional indication that our simple method in computing the gridded number of snowfall days gives reasonable results. For example, both data sets show ratios between 0.9 and 1 above $1700 \mathrm{~m}$ asl. In the Swiss lowlands, a value near 0.4 is obtained with both approaches.

In this study, future estimates of the number of snow days are based on expected temperature change only. Any possible change in wet day frequency is not accounted for, i.e., we assumed that the wet day frequency stays constant. This simplification is made since precipitation projections for Switzerland are inconclusive (Fischer et al. 2011), in particular for winter, spring and fall. In addition, the delta-change approach should not be applied on precipitation data for reasons that are discussed later.

\section{Results}

The results are split into indices that depend only on temperature (Subsection 3.1) and the number of days with fresh snow, which also depend on precipitation (Subsection 3.2). Within these subsections, a spatial analysis is performed. The altitude-dependence is discussed as well.

\subsection{Temperature-based indices}

Figure 4 shows maps of the annual mean number of summer days and tropical nights in the reference period (1980-2009) and the future scenario period 2070-99 for the emission scenarios A1B and RCP3PD. A2 is not shown as a map due to its similarity with A1B. The altitude-dependence is displayed for all greenhouse gas emission scenarios. The scenario A2, as well as the periods 2020-49 and 2045-74 are presented as supplementary material to this article (Supplementary Material). The lines in Fig. $4 \mathrm{~d}$ and h correspond to the median values of all grid points over height bins of $100 \mathrm{~m}$. The black lines correspond to the reference period 1980-2009. The shaded regions display the values between the lower and upper 


\section{Summer days}

(a) Observations

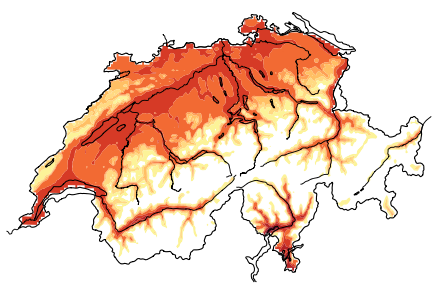

(b) RCP3PD, 2070-99

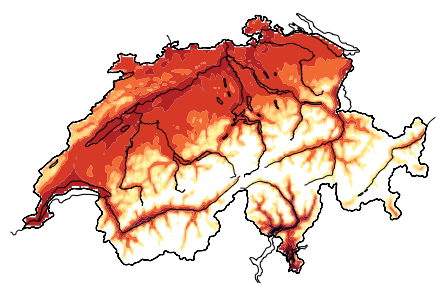

(c) $\mathrm{A} 1 \mathrm{~B}, 2070-99$
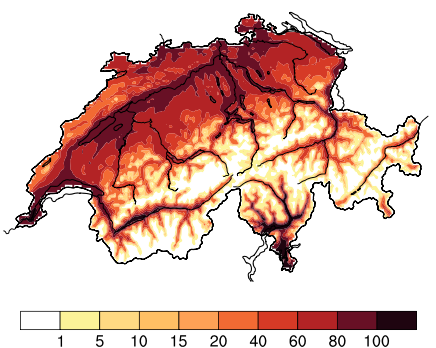

Number of summer days

(d) All scenarios, 2070-99

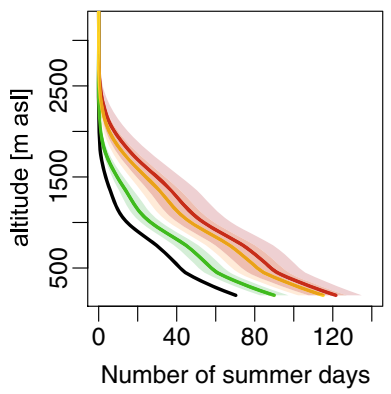

Tropical nights

(e) Observations

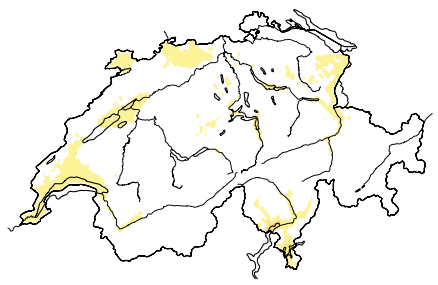

(f) RCP3PD, 2070-99

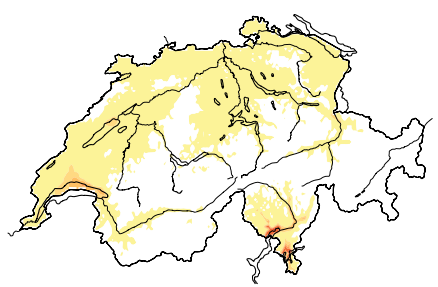

(g) A1B, 2070-99
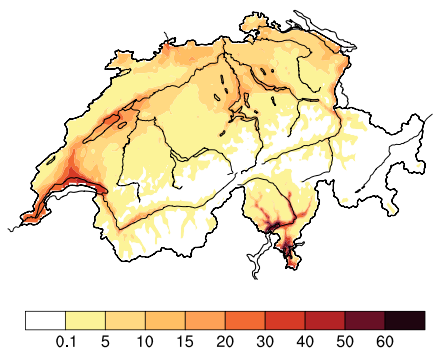

Number of tropical nights

(h) All scenarios, 2070-99

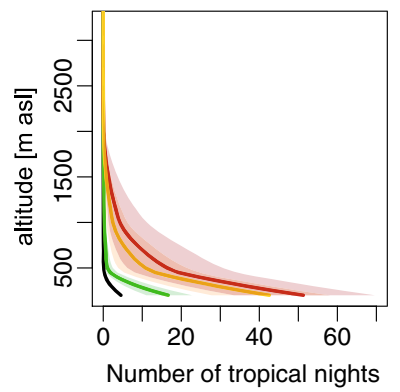

Fig. 4 Number of summer days (left) and tropical nights (right): a, e 30-year mean over observations in the reference period 1980-2009, median estimates of b, f RCP3PD-scenario (2070-99) and c, $\mathbf{g}$ A1B-scenario (2070-99). d, h Vertical structure for all scenarios. In $\mathbf{d}, \mathbf{h}$ the black line indicates the observations. The scenarios are displayed as follows: RCP3PD (green), A1B (yellow), and A2 (red). The lines in $\mathbf{d}$, $\mathbf{h}$ correspond to medians of height bins of $100 \mathrm{~m}$ over all grid points within Switzerland. Shading indicates the range from the lower and the upper estimate of each greenhouse gas scenario, respectively. Spatial variability is not displayed the in bottom panels 
estimate of each emission scenario. These values are also generated by taking the median over the height bins for the respective estimates.

Given a warming of approximately $4{ }^{\circ} \mathrm{C}$ by the end of the century in $\mathrm{A} 1 \mathrm{~B}$ and $\mathrm{A} 2$, the largest absolute increase in the number of summer days is projected for the Swiss lowlands, the Rhone river valley, as well as the Ticino. In the reference period, hardly any regions exhibit more than 100 days with a maximum temperature above $25^{\circ} \mathrm{C}$. At the end of the $21 \mathrm{st}$ century, however, almost all of the lower Ticino may experience more than three months of summer days with the A1B scenario. An increase by about 1.5 months is found in the present study. The region without any summer days in the period 2070-2099 (white band in the Alps) is expected to shrink considerably.

In relative terms, almost a doubling can be found for the A1B and A2 scenario up to about $800 \mathrm{~m}$ asl. Above, the relative increase is even stronger, mainly due to the infrequent occurrence of summer days in the reference period at these altitudes.

In the period 2070-2099, a few summer days per year may be observed even at altitudes higher than $2500 \mathrm{~m}$ asl. Currently, days with maximum temperatures above $25^{\circ} \mathrm{C}$ are only observed below $1800 \mathrm{~m}$ asl. In order to experience the same amount of summer days as in the reference period, one may have to go between 700 and $1000 \mathrm{~m}$ higher at the end of the 21 st century.

The range of expected values due to different emission scenarios is about 30 days per year for the annual mean number of summer days. The model projection uncertainty, expressed by the lower and upper estimates for each scenario, is of the order of $\pm 10-15$ summer days in the lowest parts of Switzerland, where the largest absolute increase is projected.

The number of tropical nights (right column in Fig. 4) indicates possible heat stress for organisms (Sillmann and Roeckner 2008). It increases from almost none today to about 50 at the end of the 21 st century in the A1B and A2 scenario in the Ticino and 5-20 in most parts of the Swiss lowlands. In other words, more than one and a half months of tropical nights may be possible for the lowest parts of Switzerland in the future climate. Note also that tropical nights may be observed at altitudes above $1500 \mathrm{~m}$ asl. The model projection uncertainty for both summer days and tropical nights roughly amounts to \pm 10 days/nights in 2070-99.

It is important to note that the expected end-of-the-century changes in key indices depend clearly on the different emissions scenarios. Hence, the greenhouse gas emission scenarios play an important role for the quantification of potential impacts of climate change on economy, ecology and society. Under the RCP3PD scenario summer days would only increase by about 2-3 weeks in the Swiss lowlands and remain roughly constant throughout the 21 st century. Consistently, also tropical nights and other climatic indices do not show such strong changes under RCP3PD as compared to A1B or A2. The similarity of A1B and A2 is explained by the fact that the total amount of greenhouse gases is similar for the two emission scenarios, thus leading to relatively similar (global) temperature changes in the $21 \mathrm{st}$ century.

The number of frost days, ice days and the growing season length is shown in Fig. 5. In A1B (and A2), frost days will decrease strongly at lower levels in the Ticino and along Lake Geneva by the end of the century. While in the reference period typical numbers for the lower part of Switzerland are in the range of 75 to 125 days, many regions in the North of Switzerland will possibly experience less than 50 frost days per year, assuming the A1B scenario. At high locations in the Alps, up to 2 months less frost days must be expected. Areas with about 1/3 of a year being frost days (blue shading in left column of Fig. 5) roughly correspond to the regions without any summer days. The retreat of these areas to higher locations in the Alps is also illustrated in the number of frost days. 
(a) Obrost days

(a) Observations

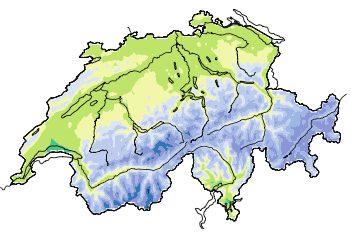

(b) RCP3PD, 2070-99

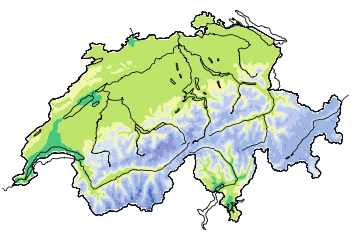

(C) A1B, 2070-99
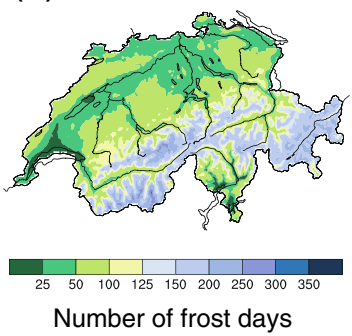

(d) All scenarios, 2070-99

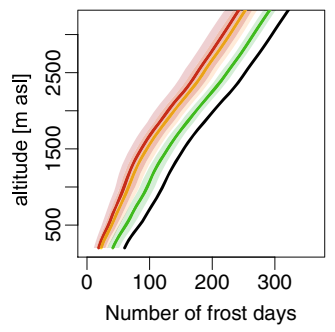

Ice days

(e) Observations

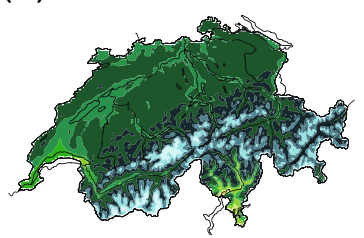

(f) RCP3PD, 2070-99

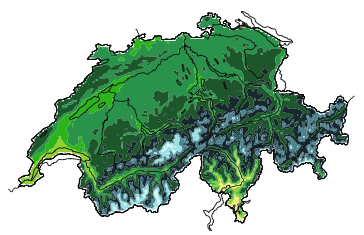

(g) A1B, 2070-99
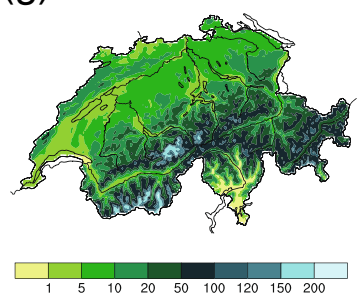

Number of ice days

(h) All scenarios, 2070-99

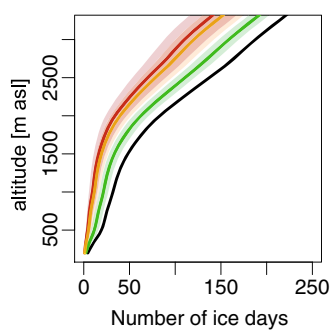

Growing season length

(i) Observations

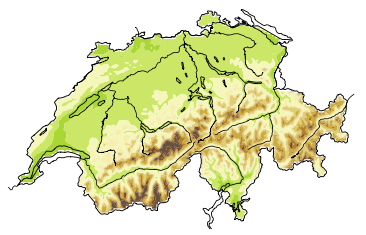

(j) RCP3PD, 2070-99

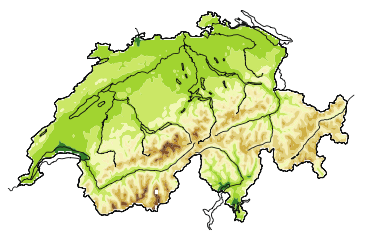

(k) A1B, 2070-99

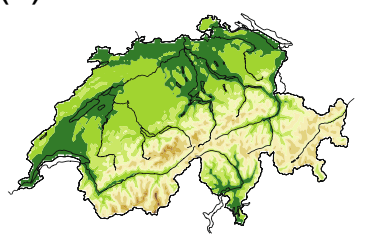

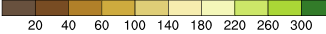
Growing season length [d]

(I) All scenarios, 2070-99

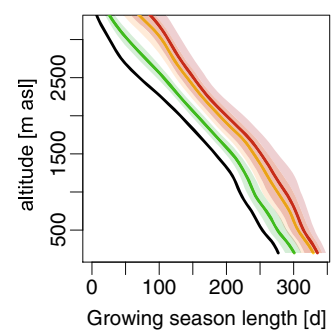

Fig. 5 Similar to Fig. 4, but for the number of frost days, the number of ice days and the growing season length. The latter is given in units of days (d)

Regions in the lower areas of Switzerland are already characterized with rare ice days occurrence. In these regions ice days may almost disappear in the scenarios A1B or A2. However, at higher levels the impact of a warming atmosphere on the frequency of ice days is most dramatic under the assumption of the business-as-usual scenarios. A reduction of about $30 \%$ can be expected above $3000 \mathrm{~m}$ asl. This may endanger permafrost layers and, thus, cause destabilization of the solid underground in many Alpine regions and cause rockfall (Gruber et al. 2004). Again, the results strongly depend on the chosen emission scenario. In the RCP3PD scenario the response is a lot weaker than in A1B or A2. The model projection uncertainty is of similar magnitude for frost and ice days as it is for the summer days and tropical nights. 
Under current climate, the thermal growing season length has a typical duration of about 240 days or two thirds of a year in the Swiss lowlands. In the lowest regions of the Ticino, 270 days are observed today. Typically, the growing season begins in early March and ends at the end of October in the lowest few hundred meters of Switzerland. The growing season length exhibits an almost linear decrease with increasing altitude and is very highly anticorrelated with the number of frost days (Frich et al. 2002). By the end of the century, the growing season may be prolonged by about 50 days or 1.5 months in $\mathrm{A} 1 \mathrm{~B}$ and $\mathrm{A} 2$. The RCP3PD scenario projects only an increase of about 20 days. In the Swiss lowlands, more than 320 days of growing season could be expected under the A1B or A2 scenario for the latest 30 -year period of the 21 st century. Hence, in a future climate the growing season is likely to start already in mid- or early February and may last until mid-November in these regions.

As temperatures are expected to rise in Switzerland, the heating energy demand will drop. This can be expressed by the change in heating degree days (HDD). Often a proportional relationship between heating degree days and heating energy demand is assumed, such that $1 \%$ change in HDD corresponds to $1 \%$ change in energy demand as well (Christenson et al. 2006). Figure 6 shows the absolute number of heating and cooling degree days in the reference and future period (2070-99) similarly as the previously discussed indices. In absolute terms, about 1000-2000 Kd less are expected in A1B and A2 by the end of the century, the vertical structure of the change being relatively homogenous. In 2070-99 a reduction of energy demand for heating of 27-30\% can be expected with the A1B and A2 scenario. This is true for the lowermost $1500 \mathrm{~m}$, which encapsulate the Swiss lowlands, the Jura in the north as well as a large part of the slopes along the Alpine rim. At higher altitudes, the relative change in HDD becomes smaller, such that above $3000 \mathrm{~m}$ asl, the heating energy demand only drops by about $20 \%$. However, the fraction of population living permanently at this altitude is negligibly small.

Cooling degree days (CDD) increase with the warming, in the A2 scenario by about a factor 3. Estimating the cooling energy demand from that, however, is difficult since air conditioning (AC) is not typical in Switzerland today, but might become common in the future. Therefore, a proper estimate of the energy demand for cooling would have to include information on how many households and companies would install an $\mathrm{AC}$ until the end of the century.

\subsection{Precipitation-based indices}

Figure 7 shows the impact of the warming on the distribution of the 30-year annual mean number of days with snowfall. As explained above, the number of wet days is assumed constant. Despite the constant wet day frequency the number of days with snowfall is reduced by up to 1 month on average in A1B and A2 between the reference period and 2070-2099. The Aletsch region, typically getting more than 120 days of snowfall per year, may get no more than 100 days in the future, only taking the temperature change into account. In addition, the largest part of the Swiss lowlands will likely have less than 10 days of snowfall per year. In this region, 10-30 days of snowfall per year are observed today.

By the end of the 21 st century, the projections indicate that there will be no more days with snowfall in the lowest parts of Switzerland below $300 \mathrm{~m}$ asl. The reduction depends considerably on the chosen emission scenario. The strong reduction of days with fresh snow at high altitudes in $\mathrm{A} 1 \mathrm{~B}$ and $\mathrm{A} 2$ throughout the year may threaten Alpine glaciers due to lack of snow in their respective accumulation zones, and regions with permanent snow cover might be endangered. This could have effects on mountain hydrology as many Alpine catchments are driven by glacier discharge and/or snowmelt. This can also lead to a shift of the 


\section{Heating degree days}

(a) Observations

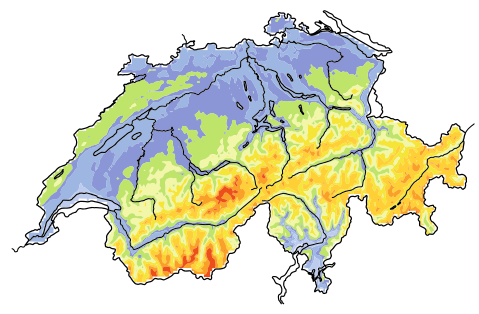

(b) RCP3PD, 2070-99

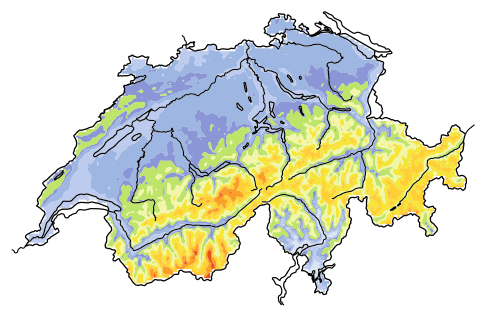

(c) A1B, 2070-99
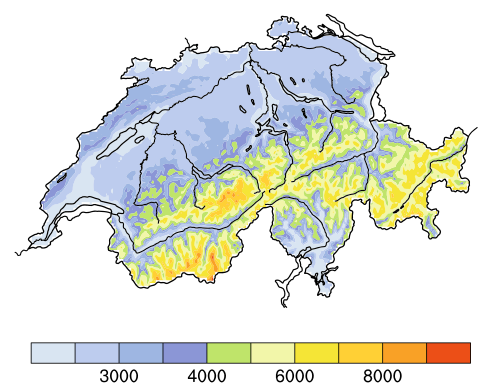

Heating degree days $[\mathrm{Kd}]$

(d) All scenarios, 2070-99

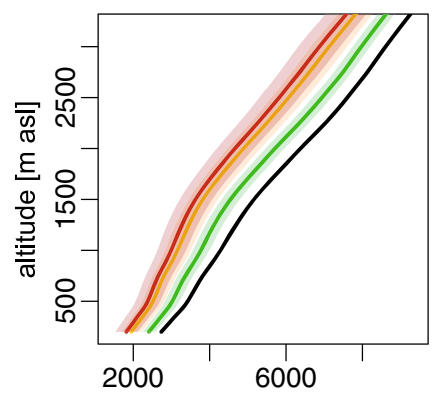

Heating degree days [Kd]

\section{Cooling degree days}

(e) Observations

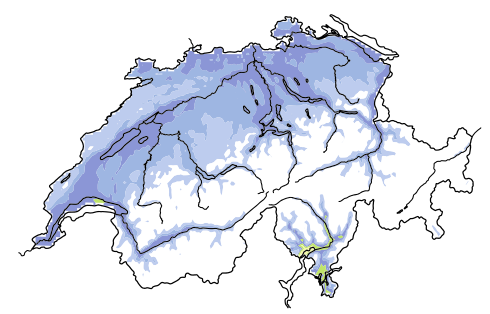

(f) RCP3PD, 2070-99

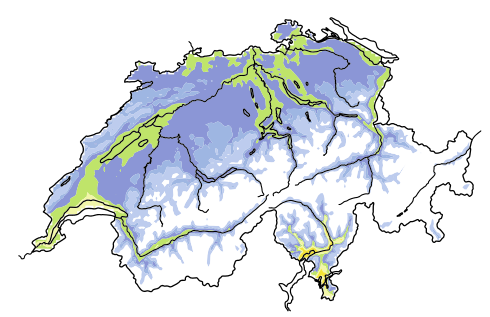

(g) $\mathrm{A} 1 \mathrm{~B}, 2070-99$

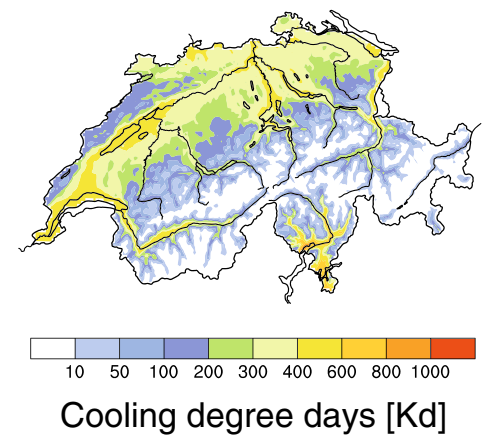

(h) All scenarios, 2070-99

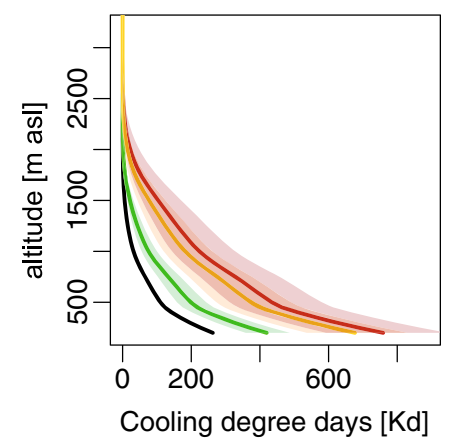

Fig. 6 The same as Fig. 4, but for heating degree days and cooling degree days 
Fig. 7 Similar to Fig. 4, but for the annual mean number of days with fresh snow (a) Observations

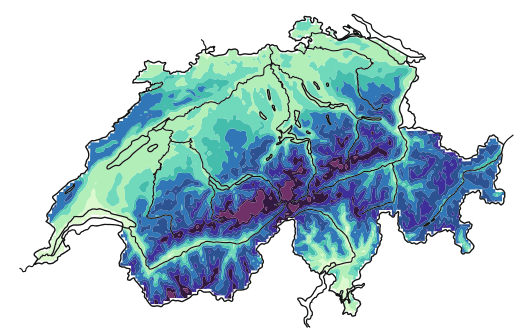

(b) RCP3PD, 2070-99

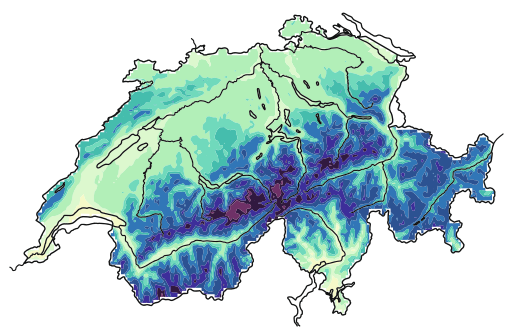

(c) A1B, 2070-99

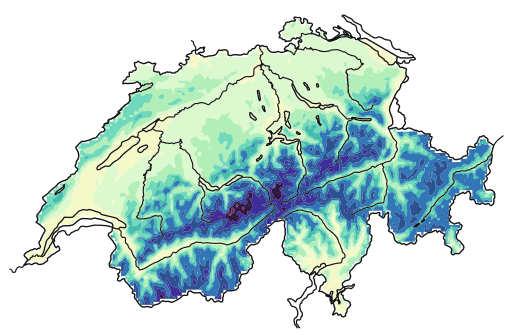

$\begin{array}{lllllllll}5 & 10 & 20 & 30 & 40 & 60 & 80 & 100 & 120\end{array}$

Number of days with fresh snow

(d) All scenarios,

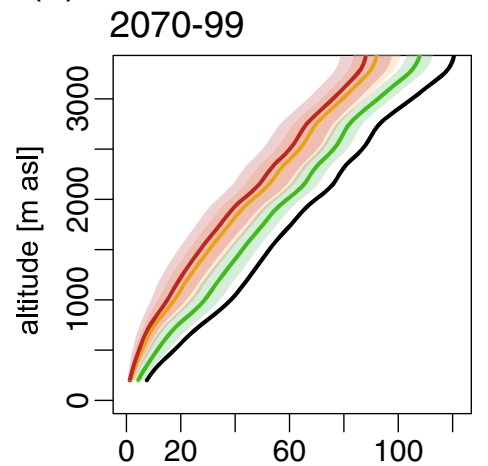

Number of days with fresh snow 


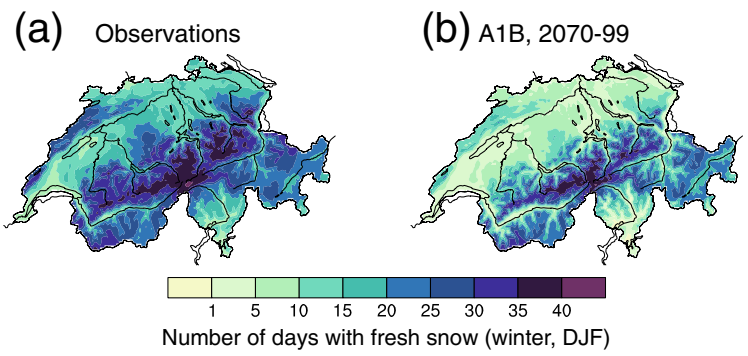

Fig. 8 Similar to Fig. 7, but for the winter season (DJF) and the A1B-scenario only. (c) shows the difference between A1B (2070-99) and the observations in the reference period (1980-2009)

discharge peak to earlier in the year (Köplin et al. 2013). Please note at this point that our analysis does not give insight on the change in the amount of snowfall per day, which is of equal importance as the change in frequency. However, it is reasonable to assume that in a warming climate not only the number of snowfall events declines, but also the mean amount of falling snow since the latter melts more likely on its way to the surface (Serquet et al. 2011; Kotlarski et al. 2012).

Figure 8 shows the changes in days with fresh snow for the winter season (DJF) only. In current climate, up to about 40 days of snowfall are observed in the Alps. The Swiss lowlands receive snow on roughly 10-20 days. Along the northern Alpine rim and in the Jura, $20-40$ days are common. This region with an altitude of around $1200-1600 \mathrm{~m}$ asl is where the largest reduction is expected under A1B (up to about 14 days less, or a reduction by $30-50 \%$ ). Hence, particularly lower ski resorts in this area might need to adapt to the consequences of the warming climate. In the highest regions of the Alps, our data set indicates that snowfall will not change in winter, but we assume a constant wet day frequency. Note that in RCP3PD, the maximum change in winter is only about -5 days with snowfall (not shown).

We also find a reduction of the snow days to wet days ratio by $20-30 \%$ in the Swiss lowlands and 30-40\% along the Northern Alpine flank between 800 and $1800 \mathrm{~m}$ asl.

\section{Discussion and conclusions}

The present study used a localized gridded data set of climate change signals for mean temperature and mean precipitation together with a gridded observational daily temperature and precipitation data set to quantify the present and possible future developments of key climate indices over Switzerland. A spatial analysis was performed and vertical profiles were analyzed. The focus of the article was on end-of-the-century projections (2070-99), but the earlier periods (2020-49, 2045-74) are provided as supplementary material.

It was shown that due to approximately $4{ }^{\circ} \mathrm{C}$ warming in most of Switzerland the number of summer days in the lowlands is roughly doubled by the end of century when comparing with the reference period 1980-2009. Tropical nights occur above $1500 \mathrm{~m}$ asl in the last 30 years of the 21 st century. Frost days are reduced by more than 50 days in the A1B and A2 emission scenario. The number of ice days even declines by about 90 days above 3000 $\mathrm{m}$. The growing season length extends from February to November in the lowest parts of Switzerland under A1B and A2, which corresponds to a prolongation by roughly 50 days. The intervention emission scenario RCP3PD, however, showed much smaller impact on temperatures and related indices. 
A reduction of the heating degree days (a proxy for energy demand) by $30 \%$ can be expected until the end of the 21 st century, and cooling degree days are likely to increase by about a factor 3 compared to present levels in the Swiss lowlands in A1B and A2.

It is clear, that our comparatively simple approach for generating possible future daily data sets has a number of limitations. Most of these limitations are inherent to model-based climate change studies (Stoeckli et al. 2008) or are in particular linked to the delta-change approach as discussed below. One of the important limitations is that the wet day frequency was assumed constant. The delta-change approach should not be applied to threshold-based precipitation indices such as wet day frequency because a mean shift of daily precipitation will lead to artificial changes in wet days, e.g., when the threshold of $1 \mathrm{~mm}$ is exceeded more often. Nevertheless, days with snowfall will be reduced due to the strong temperature change in the A1B- and A2-scenario. A maximum of about 1 month less days with snowfall is a common estimate for a large range of altitudes from about $1500 \mathrm{~m}$ to $3000 \mathrm{~m}$ asl. In winter, the pattern of change regarding the number of snowfall days is substantially different because, on average, the melting level is lower. As a consequence, the largest reduction in the number of snowfall days is found along the Northern Alpine flank and the Jura (roughly -10 days until 2070-2099). Above $2000 \mathrm{~m}$ asl, the change is small ( -2 to 0 days).

The projected mean temperature change signals from Zubler et al. (2013) that are applied in this article all exceed natural decadal variability. For all temperature-based indices discussed herein, the change signals of the median estimates in 2045-74 and 2070-99 are even stronger than the interannual variability of the respective indices in the reference period ( \pm 1 standard deviation, not shown). Hence, the projected change of the key indices towards the end of the century is on average even larger than annual fluctuations today.

The computation of the growing season length from temperature alone did not include snow cover, radiation or other possible influences due to the lack of data.

As discussed previously, these climate indices make climatic change and its impacts more comprehensible. The changes associated with a shift of the temperature distribution by a constant (delta-change approach), such as the increase in the number of summer days and tropical nights, combined with the decrease of frost and ice days, are likely to pose substantial challenges in adaptation for local and national authorities (FOEN 2012).

The major limitations of the delta-approach are the implicit assumption of constant shape of the distributions of temperature and the assumption of constant bias of the underlying numerical models (Bosshard et al. 2011), i.e., in a model with an increasing temperature bias the change signal obtained by subtracting the reference temperature from the projection is probably overestimated (Christensen et al. 2008). Furthermore, using the same delta on both daily minimum and mean temperature may not be appropriate (Sillmann and Roeckner 2008). Studies of climatic extremes often highlight the importance of considering the change of the standard deviation, e.g., that of temperature, to explain the augmented likelihood of occurrence for heat waves or droughts or other extreme events. Therefore, future studies of climate indices in Switzerland should also include changes to the temperature and precipitation distributions beyond altering mean values.

\footnotetext{
Acknowledgments The author wishes to thank the anonymous reviewers for their valuable comments as well as the following people for the fruitful discussions or helpful pieces of advice: D. Keller, A. Fischer, R. Posselt, T. Schlegel, M. Begert and S. Kotlarski. C. Frei is thanked for providing the highly localized gridded observations of temperature. Prof. C. Schär is acknowledged for his help with the computation of the scenarios on daily resolution based on seasonal data. The $\mathrm{CH} 2011$ data were obtained from the Center for Climate Systems Modeling (C2SM). The Swiss Federal Office for the Environment (FOEN) is financing a major part of the present study.
} 


\section{References}

American Society of Heating Refrigerating and Air-Conditioning Engineers (ed.) (2001) Energy estimating and modeling methods, chap 31, SHRAE, Atlanta

Baeriswyl PA, Rebetez M (1997) Regionalization of precipitation in Switzerland by means of principal component analysis. Theor Appl Climatol 58:31-41

Begert M, Seiz G, Foppa N, Schlegel T, Appenzeller C, Müller G (2007) Die Überführung der klimatologischen Referenzstationen der Schweiz in das Swiss National Basic Climatological Network (Swiss NBCN). Arbeitsberichte der MeteoSchweiz 215, MeteoSwiss

Bosshard T, Kotlarski S, Ewen T, Schär C (2011) Spectral representation of the annual cycle in the climate change signal. Hydrol Earth Syst Sci Discuss 8:1161-1192. doi:10.5194/hessd-8-1161-2011

Buser CM, Künsch HR, Lüthi D, Wild M, Schär C (2009) Bayesian multi-model projections of climate: bias assumptions and interannual variability. Clim Dyn 33:849-868. doi:10.1007/s00382-009-0588-6

Cerutti B, Tereanu C, Domenighetti G, Cantoni E, Gaia M, Bolgiani I, Lazzaro M, Cassis I (2006) Temperature related mortality and ambulance service interventions during the heat waves of 2003 in Ticino (Switzerland). Soz Praventiv Med 51(4):185-193. doi:10.1007/s00038-006-0026-Z

CH2011 (ed.) (2011) Swiss climate change scenarios CH2011. C2SM, MeteoSwiss, ETH, NCCR climate, and OcCC, Zurich

Christensen JH, Boberg F, Christensen OB, Lucas-Picher P (2008) On the need for bias correction of regional climate change projections of temperature and precipitation. Geophys Res Lett 35(L20709). doi:10.1029/2008GL035694

Christenson M, Manz H, Gyalistras D (2006) Climate warming impact on degree-days and building energy demand in Switzerland. Energ Convers Manage 47:671-686. doi:10.1016/j.enconman.2005.06.009

Dramis F, Govi M, Guglielmin M, Mortara G (1995) Mountain permafrost and slope instability in the Italian Alps: the Val Pola landslide. Permafr Periglac Process 6(1):73-81. doi:10.1002/ppp.3430060108

Fischer AM, Weigel AP, Buser CM, Knutti R, Künsch HR, Liniger MA, Schär C, Appenzeller C (2011) Climate change projections for Switzerland based on a Bayesian multi-model approach. Int J Climatol. doi:10.1002/joc.3396

Fischer EM, Schär C (2010) Consistent geographical patterns of changes in high-impact European heatwaves. Nat Geosci 3:398-403. doi:10.1038/ngeo866

FOEN (2012) Adaptation to climate change in Switzerland-goals, challenges and fields of action: first part of the Federal Council's strategy. Tech. rep., Federal Office for the Environment

Frei C (2013) Interpolation of temperature in a mountainous region using non-linear profiles and noneuclidean distances. Int J Climatol 58. doi:10.1002/joc.3786

Frei C, Schär C (1998) A precipitation climatology of the alps from high-resolution rain-gauge observations. Int J Climatol 18:873-900

Frich P, Alexander LV, Della-Marta P, Gleason B, Haylock M, Tank AMGK, Peterson T (2002) Observed coherent changes in climatic extremes during the second half of the twentieth century. Clim Res 19:193212

Gruber S, Haeberli W (2007) Permafrost in steep bedrock slopes and its temperature-related destabilization following climate change. J Geophys Res Earth Surf 112(F2). doi:10.1029/2006JF000547

Gruber S, Hoelzle M, Haeberli W (2004) Permafrost thaw and destabilization of Alpine rock walls in the hot summer of 2003. Geophys Res Lett 31:L13504. doi:10.1029/2004GL020051

Karl TR, Nicholls N, Ghazi A (1999) CLIVAR/GCOS/WMO workshop on indices and indicators for climate extremes: workshop summary. Clim Change 42:3-7

Klein Tank AMG, Können GP (2003) Trends in indices of daily temperature and precipitation extremes in Europe, 1946-99. J Clim 16:3665-3680

Klein Tank AMG, Zwiers FW, Zhang X (2009) Guidelines on analysis of extremes in a changing climate in support of informed decisions for adaptation. WMO-TD 1500, World Meteorological Organization (WMO)

Köplin N, Schädler B, Viviroli D, Weingartner R (2013) Seasonality and magnitude of floods in Switzerland under future climate change. Hydrol Process. doi:10.1002/hyp.9757

Kotlarski S, Bosshard T, Lüthi D, Pall P, Schär C (2012) Elevation gradients of European climate change in the regional climate model COSMO-CLM. Clim Change 112:189-215. doi:10.1007/s10584-011-0195-5

Kovats RS, Hajat S, Wilkinson P (2004) Contrasting patterns of mortality and hospital admissions during hot weather and heat waves in Greater London. J Occup Environ Med 321:670-673

Krautblatter M, Funk D, FK Günzel (2013) Why permafrost rocks become unstable: a rock-ice-mechanical model in time and space. Earth Surf Proc Land 38(8):876-887. doi:10.1002/esp.3374 
Levitt J (1962) A sulfhydryl-disulfide hypothesis of frost injury and resistance in plants. J Theor Biol 3(3):355-391. doi:10.1016/S0022-5193(62)80032-0

van der Linden P, Mitchell JFB (2009) ENSEMBLES: climate change and its impacts: summary of research and results from the ENSEMBLES project. Met Office Hadley Centre, Exeter. doi: $10.1029 / 2004$ GL020255

Marty C (2008) Regime shift of snow days in Switzerland. Geophys Res Lett 35(12):L12501. doi:10.1029/2008GL033998

Meinshausen M, Smith SJ, Calvin KV, Daniel JS, Kainuma MLT, Lamarque JF, Matsumoto K, Montzka SA, Raper SCB, Riahi K, Thomson AM, Velders GJM, van Vuuren D (2011) The RCP greenhouse gas concentrations and their extension from 1765 to 1230. Clim Change (Special Issue). doi:10.1007/s10584-011-0156-z

Peterson TC, Folland C, Gruza G, Hogg W, Mokssit A, Plummer N (2001) Report on the activities of the working group on climate change detection and related Rapporteurs 1998-2001, WMO-TD 1071, vol WCDMP-47. WMO, Geneva

Schüepp M, Gensler G (1980) Klimaregionen der Schweiz. In: Müller G (ed) Die Beobachtungsnetze der Schweizerischen Meteorologischen Anstalt, no. 93 in Arbeitsbericht der Schweizerischen Meteorologischen Zentralanstalt. Schweizerische Meteorologische Anstalt, Zürich

Serquet G, Marty C, Dulex JP, Rebetez M (2011) Seasonal trends and temperature dependence of the snowfall/precipitation-day ratio in Switzerland. Geophys Res Lett 38(12):L07703. doi:10.1029/ 2011GL046976

Sillmann J, Roeckner E (2008) Indices for extreme events in projections of anthropogenic climate change. Clim Change 86(1-2):83-104

Solomon S, Qin D, Manning M, Chen Z, Marquis M, Averyt K, Tignor M, Miller H (eds) (2007) Climate change 2007: the physical science basis. Contribution of working group I to the fourth assessment report of the intergovernmental panel on climate change. Cambridge University Press, New York

Steinacker R (1983) Diagnose und Prognose der Schneefallgrenze. Wetter und Leben 35:81-90

Stoeckli R, Lawrence DM, Niu GY, Oleson KW, Thornton PE, Yang ZL, Running SW (2008) Use of FLUXNET in the community land model development. J Geophys Res 113(G1):2005-2012

Swiss Association of Engineers and Architects (1982) SIA Standard 381/3: heating degree-days in Switzerland. Zurich

Zubler EM, Fischer AM, Croci-Maspoli M, Scherrer SC, Appenzeller C (2013) Localized climate change scenarios of mean temperature and precipitation over Switzerland. Clim Change 